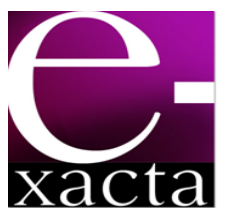

ISSN: 1984-3151

\section{AVALIAÇÃO DO USO DE RESÍDUOS SIDERÚRGICOS PARA DESCOLORAÇÃO DE EFLUENTES DE INDÚSTRIAS TÊXTEIS}

\author{
EVALUATION OF THE USE OF STEEL WASTE FOR DISCOLORATION
} WASTEWATER FROM TEXTILE INDUSTRIES

\author{
Alisson Henrique Marques da Silva'; Jorge David Alguiar Bellido²; Maikel Laurence \\ Maloncy $^{3}$; Marcelo da Silva Batista ${ }^{4}$ \\ 1 Bacharel em Engenharia Química. UFSJ, 2013. Mestrando \\ em Engenharia química - PPGEQ/UFSCar. São Carlos, SP. \\ alisson_eq@hotmail.com \\ 2 Doutor. USP/2008. Professor da UFSJ. Ouro Branco, MG. \\ jorgeb@ufsj.edu.br \\ 3 Doutor. Delft University of Technology, 2006. The Hague \\ University of Applied Sciences. The Hague, Holanda. \\ m.l.maloncy@hhs.nl \\ 4 Doutor em Engenharia Química. UFSCar/2002. Professor \\ da UFSJ. Ouro Branco, MG. marcelobatista@ufsj.edu.br
}

Recebido em: 02/09/2014 - Aprovado em: 20/11/2014 - Disponibilizado em: 30/11/2014

RESUMO: Neste trabalho avaliou-se o uso de resíduos industriais da laminação, têmpera e aciaria, para descoloração do corante azul de metileno em processo contínuo. Esses resíduos foram caracterizados por difratometria de raios $X(D R X)$ e avaliados como catalisadores na descoloração do azul de metileno. Os resultados de DRX mostraram a presença de hematita nos resíduos industriais. No processo contínuo de descoloração do corante azul de metileno, na presença de peróxido de hidrogênio e ácido, foi observada a descoloração da solução para os três resíduos. No entanto, a ordem de atividade dos resíduos foi: têmpera (20\%) < aciaria (70\%) < laminação (80\%). O resíduo de laminação também apresentou maior estabilidade catalítica nas condições da reação e mostrou-se promissor para o tratamento de efluentes de indústrias têxteis.

PALAVRAS-CHAVE: Resíduo industrial. Tratamento de efluente. Corante.

ABSTRACT: In this work the use of industrial waste from the lamination, quenching and steel mill step in the continuous process of decolorization of methylene blue dye was studied. The wastes were characterized by $X$-ray diffraction (XRD) and evaluated as catalysts in the decolorization of methylene blue. XRD results showed the presence of hematite in the industrial wastes. Decolorization was observed in the continuous process of decolorization of methylene blue dye, in the presence of hydrogen peroxide and acid, when applying the three industrial wastes. The order of activity was waste from quenching (20\%) < steel mill $(70 \%)<$ lamination (80\%). The waste from lamination also showed higher catalytic stability under the reaction conditions, and showed potential for the treatment of effluents from textile industries.

KEYWORDS: Treatment of Industrial waste. Dye.

\section{INTRODUÇÃO}

Um dos desafios que a humanidade enfrenta no século XXI é o da utilização dos resíduos e seu gerenciamento. A produção mundial chega a milhões de toneladas por dia, tornando-se necessária a sua disposição adequada. As empresas e a comunidade 
científica buscam soluções para o desenvolvimento de tecnologias capazes de minimizar os custos econômicos e os impactos decorrentes da disposição dos resíduos (MARTINS, 2006).

A indústria do aço produz mundialmente 780 milhões de toneladas de aço bruto por ano e, paralelamente, 30 milhões de toneladas de resíduos. No Brasil, a produção de aço anual é de 25 milhões de toneladas, e são gerados cerca de 1,2 milhões de toneladas de resíduos recicláveis por ano. Os principais resíduos sólidos recicláveis numa usina siderúrgica integrada são: as poeiras da sinterização; os pós e as lamas de alto-forno; as lamas de aciaria; as carepas de lingotamento contínuo; as carepas de escarfagem; as lamas de laminação e os finos de coque. A recuperação dos valores metálicos contidos nos resíduos sólidos passou a ser muito importante tanto do ponto de vista das restrições legais impostas pelas legislações relativas à proteção do meio ambiente quanto do ponto de vista econômico, por contribuírem para a compensação dos custos de instalação e operação de equipamentos antipoluição instalados nas usinas. Embora a reciclagem da maior parte (80\%) dos resíduos sólidos ricos em ferro, via sinterização, seja uma prática siderúrgica comum, esta diminui a permeabilidade do leito da carga e, consequentemente, a perda da produtividade da sinterização (CUNHA et. al., 2006). No entanto, parte do resíduo não reciclado poderia ser aproveitada para o tratamento de efluentes em outras indústrias (OLIVEIRA; FABRIS; PEREIRA, 2013). Recentemente, alguns autores têm sugerido o uso de óxidos de ferro no tratamento de efluentes têxteis (DANTAS; MENDONÇA; JOSÉ, 2006; MACHADO, 2007), visando, sobretudo, à descoloração e à degradação de corantes. Esse interesse se deve à necessidade de buscar uma solução economicamente viável para o tratamento dessa problemática classe de efluentes.
Dentre as atividades industriais consideradas como grande potencial poluidor, segundo a resolução CONAMA 237/97, destaca-se a indústria têxtil. Esse destaque é devido a três fatores importantes: elevado consumo de água no processo de beneficiamento de fibras; baixo aproveitamento dos insumos e deficiência dos processos utilizados nas rotinas de tratamento de efluentes (MELO, 2005). Nos efluentes da indústria têxtil, a maior parte da carga orgânica dos corantes é representada por agentes engomantes (amido), sendo facilmente degradada pelos processos biológicos tradicionais. No entanto, a cor, originada por uma grande variedade de corantes reativos, tipo azo com elevado potencial carcinogênico e mutagênico, mostra-se bastante resistente a este tipo de procedimento (BRAGA et. al., 2002).

Pelo fato de as metodologias de remediação utilizadas pela indústria serem ineficientes para a remoção da cor e toxicidade, há necessidade de se desenvolver novas alternativas de tratamento. Dentre elas, os processos oxidativos avançados (POA's) merecem destaque pela elevada capacidade de degradação em tempos relativamente pequenos (CISNEROS; ESPIZONA; LITTER, 2002). Dentre os POA's conhecidos, as reações Fenton têm se apresentado como promissores para degradação de grande variedade de compostos orgânicos (NEYENS; BAEYENS, 2003). Essas reações consistem na decomposição de peróxido de hidrogênio $\left(\mathrm{H}_{2} \mathrm{O}_{2}\right)$ catalisado por íons de ferro, em meio ácido, e destacam-se por apresentarem forte poder oxidante. A reação Fenton pode ocorrer em meio homogêneo e heterogêneo, mas o heterogêneo mostra vantagens sobre os sistemas homogêneos, uma vez que esse processo não requer controle estrito de $\mathrm{pH}$, e o catalisador insolúvel pode ser facilmente regenerado e reutilizado, não gerando lodo químico, característico do processo homogêneo (PARSONS, 2004).

Vista a necessidade de alternativas para aplicações de resíduos de indústrias siderúrgicas e a dificuldade 
de remoção da cor dos efluentes gerados pelas indústrias têxteis, o presente trabalho estuda a descoloração de um corante modelo (azul de metileno) utilizando resíduos gerados em indústrias siderúrgicas em reator de leito fixo em processo contínuo.

\section{Metodologia}

Neste trabalho foram utilizados resíduos provenientes de uma indústria siderúrgica, obtidos na laminação, têmpera e aciaria. Foram observados diferentes teores de ferro nos resíduos de têmpera (60\%), laminação (65\%) e aciaria (86\%). Esses resíduos foram caracterizados por difratometria de raios $\mathrm{X}(\mathrm{DRX})$ e avaliados, sem nenhum tipo de pré-tratamento, como catalisadores no processo de descoloração do corante azul de metileno.

As análises de DRX foram realizadas pelo método do pó em um difratômetro Shimadzu 6000 com tubo de $\mathrm{Cu}$ e filtro de $\mathrm{Ni}$ operando com radiação CuKa $(\lambda=0,1542)$. A velocidade do goniômetro utilizada foi

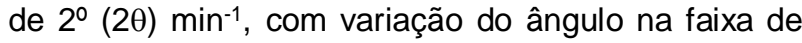
$10^{\circ}$ a $80^{\circ}$ (20). A identificação das fases cristalinas presentes nos resíduos de aciaria, laminação e altoforno foram baseadas na comparação dos difratogramas com dados publicados no (JCPDS, 1994).

$\mathrm{Na}$ preparação da solução com corante foram utilizados água destilada (2 L), ácido sulfúrico (até o $\mathrm{pH}$ do meio alcançar 2,5), peróxido de hidrogênio $(1,6$ g) e azul de metileno (40 mg). Para o controle do $\mathrm{pH}$ foi utilizado um potenciômetro.

A linha de teste catalítico utilizada para avaliação dos resíduos na reação Fenton é representada na Figura 1. A solução com corante foi bombeada $\left(60 \mathrm{~mL} \mathrm{~h}^{-1}\right)$ para o reator PBR (Plug Flow Reactor), contendo $5 \mathrm{~g}$ de resíduo. Na saída do reator, a solução foi coletada e analisada no espectrofotômetro no UV (BEL SP 2000 UV), utilizando-se um comprimento de onda adequado para o azul de metileno $(\lambda=663 \mathrm{~nm})$. Os testes foram realizados em duplicatas.

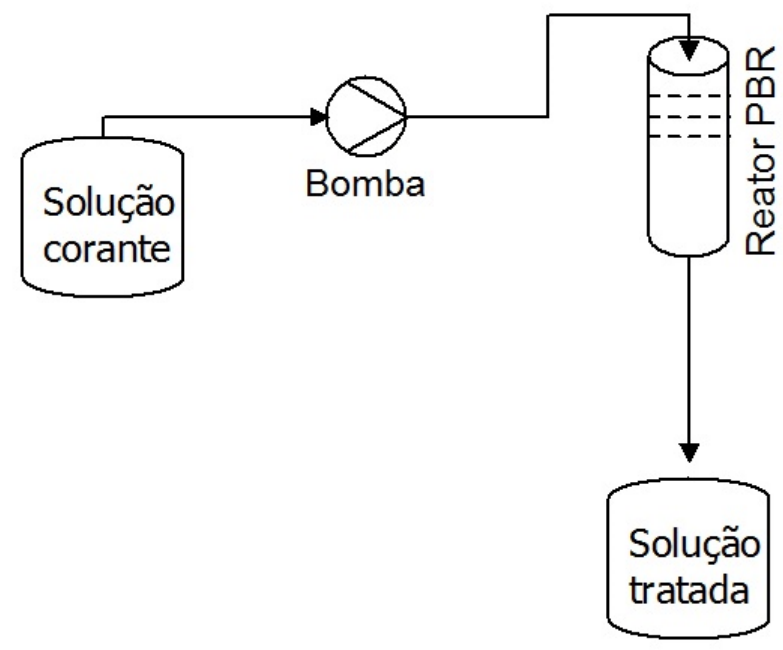

Figura 1 - Representação da linha de teste catalítico.

A porcentagem de descoloração foi calculada através da Equação 1, onde as concentrações inicial e final foram obtidas pela curva de calibração do corante no espectrofotômetro. No final do processo, a solução foi neutralizada com adição de hidróxido de sódio e descartada.

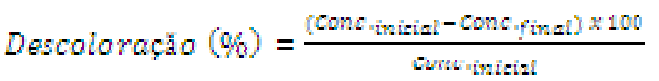

\section{RESUltAdOS E DISCUSSÃo}

O difratograma de raios $\mathrm{X}$ da amostra de resíduo de laminação é apresentado na Figura 2. Nessa figura é possível identificar os picos característicos em $2 \theta=$ $26,50^{\circ}, 49,57^{\circ}, 54,11^{\circ}$ e $56,84^{\circ}$, os quais confirmam a presença da estrutura alfa-quartzo (JCPDS ficha $n^{\circ}$ 83-2187). Outros picos característicos em $2 \Theta=33,04$, $35,41^{\circ}, 49,57^{\circ}, 54,11^{\circ}, 56,84^{\circ}, 62,46^{\circ}$ e $71,92^{\circ}$ confirmam a presença de hematita (JCPDS ficha $n^{\circ} 79$ 1741). Esta última se deve ao próprio processo de laminação, enquanto que a presença de óxido de silício em resíduos siderúrgicos, também foi observada por outros autores (MARTINS, 2006; LIMA; REIS; BORGES, 2013). 


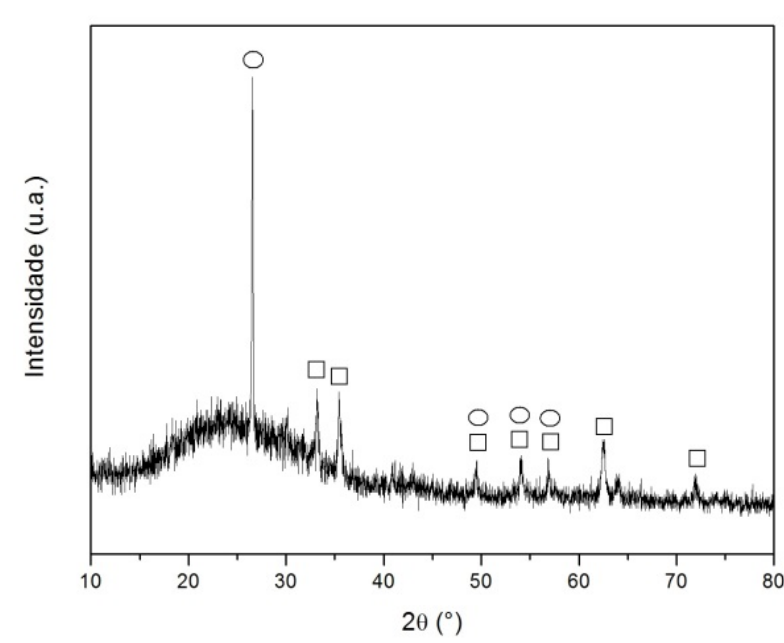

Figura 2 - DRX da amostra de laminação mostrando os picos característicos de hematita ( $\square$ ) e quartzo (०).

Na Figura 3 se apresenta o difratograma de raios $X$ da amostra de resíduos de têmpera, proveniente do alto forno. Nessa figura é possível identificar os picos característicos em $2 \Theta=33,26^{\circ}, 35,61^{\circ}, 39,42^{\circ}, 40,87^{\circ}$, $43,04^{\circ}, 49,56^{\circ}, 54,25^{\circ}, 56,97^{\circ}, 57,70^{\circ}, 62,40^{\circ}, 64,03^{\circ}$ e $72,01^{\circ}$, os quais confirmam a presença da estrutura hematita (JCPDS ficha $n^{\circ}$ 79-1741). Observa-se que o processo de têmpera, que consiste no aquecimento e resfriamento brusco do metal para aumentar a dureza, gera resíduos de hematita.

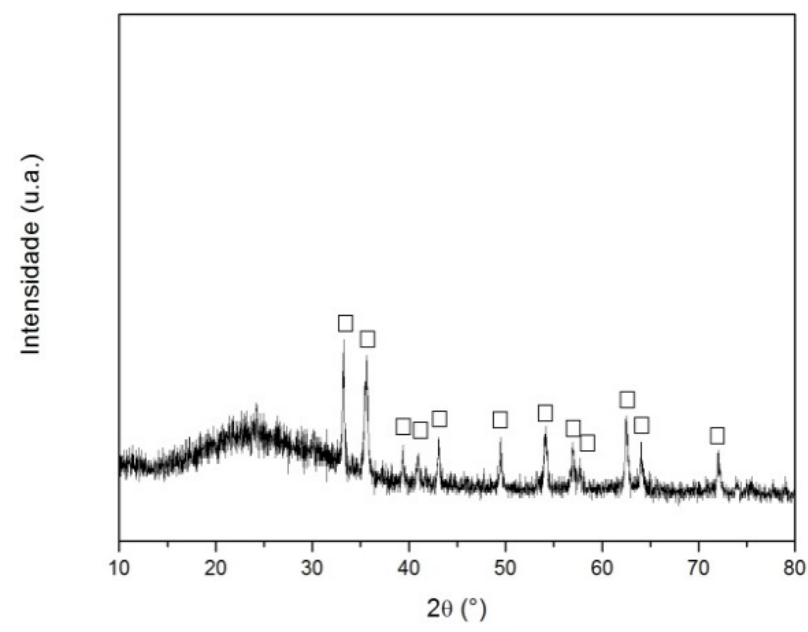

Figura 3. DRX da amostra de têmpera onde estão representados os picos característicos da hematita ( $\square$ ).
A Figura 4 apresenta o difratograma de raios $X$ da amostra de resíduos de aciaria. É possível identificar os picos característicos em $2 \Theta=33,09^{\circ}, 35,44^{\circ}$, $54,08^{\circ}, 56,60^{\circ}, 57,51^{\circ}, 62,59^{\circ}$ e $64,03^{\circ}$, os quais confirmam a presença da estrutura hematita (JCPDS ficha $n^{0}$ 79-1741). A presença desta última é esperada, pois os resíduos provenientes da aciaria envolvem o ferro gusa, o qual será transformado em diversos tipos de aço.

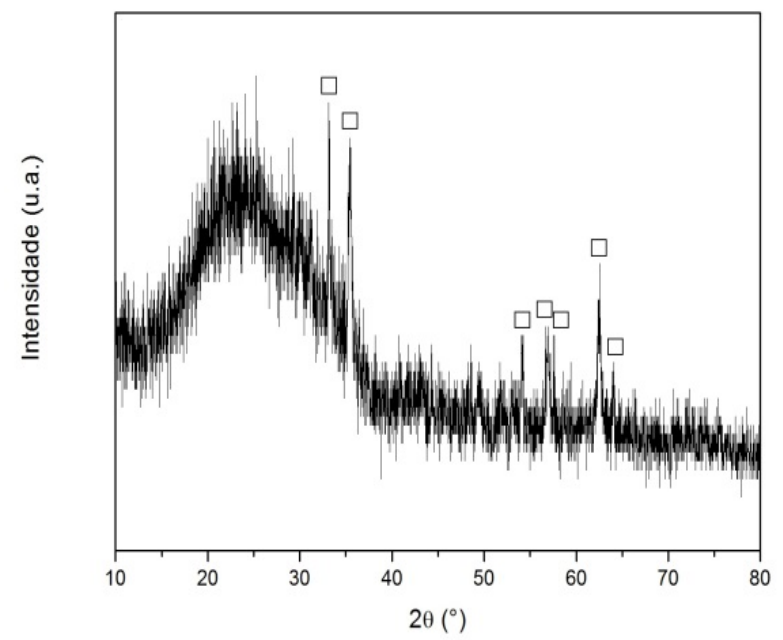

Figura 4. DRX da amostra de aciaria mostrando os picos característicos da hematita ( $\square)$.

A literatura relata que alguns corantes são instáveis, e a descoloração do corante ocorre apenas na presença de peróxido de hidrogênio e/ou luz (BANAT et al., 2005). Para avaliar o efeito do peróxido e da fotocatálise, a descoloração da solução contendo azul de metileno foi avaliada na ausência de resíduo e os resultados são apresentados na Figura 5. Nessa figura pode-se observar que não houve descoloração. Dessa forma, é possível afirmar que não ocorre descoloração do corante azul de metileno apenas na presença de ácido, peróxido de hidrogênio e luz. 


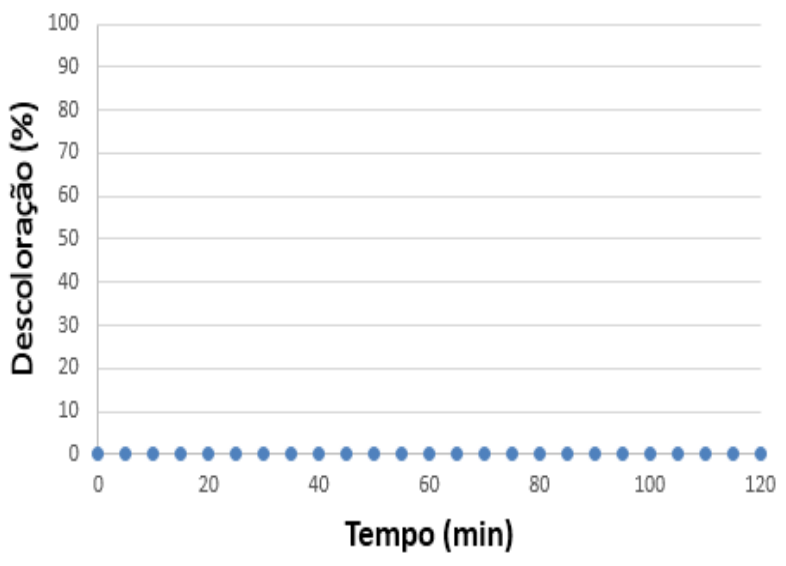

Figura 5 - Descoloração da solução corante na ausência de resíduo.

Na Figura 6, pode-se observar o comportamento da descoloração da solução corante sobre o resíduo de aciaria, laminação ou têmpera. O resíduo de têmpera apresentou inicialmente $63 \%$ de descoloração e, em trinta minutos, caiu para cerca de $20 \%$. Após essa queda inicial, a descoloração foi mantida em $20 \%$ ao longo do tempo. Essa percentagem de descoloração foi menor que as observadas nos resíduos de aciaria e laminação. Inicialmente, o resíduo de aciaria atingiu mais de $90 \%$ de descoloração, mas a atividade diminuiu e estabilizou em $70 \%$, após cerca de 60 min.

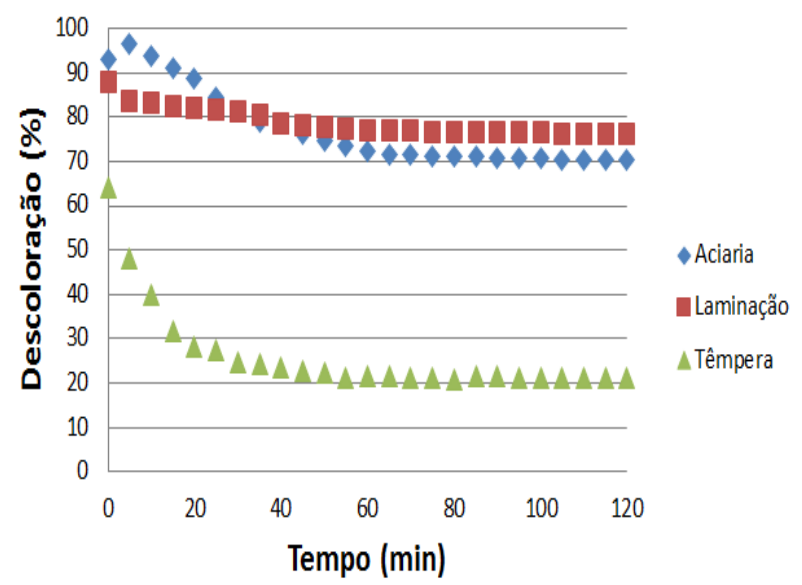

Figura 6 - Descoloração da solução corante sobre o resíduo de aciaria, laminação ou têmpera.

Por outro lado, o resíduo de laminação mostrou, inicialmente, $90 \%$ de descoloração e apresentou a menor diminuição ao longo do tempo, permanecendo em torno de $80 \%$ de descoloração. A capacidade de adsorção física dos resíduos foi previamente estudada (resultado não mostrado) e mostrou a diminuição acentuada dessa adsorção ao decorrer do tempo, provavelmente devido à colmatação dos poros, limitando sua aplicação em processos contínuos (AMORIM, 2010). Esse resultado, entretanto, comprova a existência de reação química nos resultados apresentados na Figura 6.

A atividade catalítica inicial (aciaria (95\%), laminação $(90 \%)$ e têmpera $(65 \%))$ pode estar relacionada à concentração de ferro presente nos resíduos, ou seja, quanto maior a concentração de ferro no resíduo (aciaria (86\%), laminação (65\%) e têmpera (60\%)), maior será a produção de radicais hidroxilas e, consequentemente, maior será a descoloração (ARAÚJO, 2008). Dessa forma, a menor percentagem de descoloração proveniente do resíduo de têmpera pode estar relacionada à sua menor concentração de ferro. Entretanto, a rápida desativação observada no resíduo de têmpera mostra que outros compostos não cristalinos e o acesso às espécies ativas de ferro podem estar interferindo na descoloração do corante.

Os resíduos da laminação e da aciaria apresentaram os melhores resultados na descoloração do corante azul de metileno, sendo promissora sua utilização na reação de Fenton em processo contínuo. A maioria dos trabalhos com processos oxidativos avançados é realizada em processo em batelada, sendo que o processo contínuo pode viabilizar a aplicação de resíduos da indústria siderúrgica no tratamento de efluentes provenientes de indústrias têxteis.

\section{CONCLUSÕES}

De acordo com os resultados e nas condições experimentais utilizadas, pode-se concluir que foi possível identificar, através da difratometria de raios $\mathrm{X}$, os picos característicos de hematita nos resíduos 
siderúrgicos de aciaria, laminação e de têmpera. Esses resíduos foram avaliados no processo contínuo de descoloração do corante azul de metileno, na presença de peróxido de hidrogênio e com o pH 2,5. Foi observada a descoloração da solução corante para os três resíduos utilizados. O resíduo de têmpera mostrou queda acentuada da descoloração, no início da reação, e permaneceu em aproximadamente 20\% de descoloração. O resíduo de aciaria apresentou maiores percentagens de descoloração ( 70\%), quando comparado ao resíduo de têmpera ( 20\%). Esse fato pode estar relacionado à quantidade de hematita presente nos resíduos. O resíduo de laminação apresentou os melhores resultados, obtendo cerca de $80 \%$ de descoloração do azul de metileno. Esse resíduo também apresentou menor desativação catalítica ao longo do tempo, mostrando ser mais estável nas condições da reação do que os resíduos de têmpera e da aciaria.

A aplicação do resíduo de laminação da indústria siderúrgica na descoloração do azul de metileno em processo contínuo se mostrou atrativa, devido à alta percentagem de descoloração utilizando resíduos que ainda não possuem aplicações industriais, bem como o uso de processo contínuo na descoloração de efluentes de indústrias têxteis.

\section{AGRADECIMENTOS}

Os autores agradecem ao CNPq pela bolsa de Iniciação Científica e ao apoio financeiro do projeto CAPES/BRANETEC 009/2012.

\section{REFERÊNCIAS}

AMORIM, C. C. D. Utilização de resíduo do desempoeiramento do alto forno para tratamento de efluentes. Tese de Doutorado. Departamento de Engenharia Sanitária e Ambiental. Programa de Pósgraduação em Saneamento, Meio Ambiente e Recursos Hídricos. Belo Horizonte, Universidade Federal de Minas Gerais, 2010.

ARAÚJO, F. V. F. Estudo do processo Fenton heterogêneo utilizando hematita $(\mathrm{FeO})$ como catalisador na descoloração de soluções de corante reativo. Dissertação de Mestrado.

Tecnologias de Processos Químicos e Bioquímicos. Rio de Janeiro, Universidade Federal do Rio de Janeiro, 2008.

BANAT, F.; AL-ASHEH, S.; AL-RAWASHDEH, M.; NUSAIR, M.; Photodegradation of methylene blue dye by the UV/H202 and UV/acetone oxidation processes.

Desalination. v. 181, 225-232, 2005.

BRAGA, B.; HESPANHOL, I.; CONEJO, J. G. L.; BARROS, M. T. L.; SPENCER, M.; PORTO, M.; NUCCI, N.; JULIANO, N.; EIGER, S. Introdução à Engenharia Ambiental. São Paulo: Prentice Hall, 2002.

CISNEROS, R. L.; ESPIZONA, A. G.; LITTER, M. I. Photodegradation of an azo dye of the textile industry. Chemosphere, 2002.
BRASIL. Resolução no 357 de 17 de março de 2005. Conselho Nacional do Meio Ambiente - CONAMA.

CUNHA, A. F.; A. FILHO, G.; M. JÚNIOR, A.; GOMES, O. C. B.; ASSIS, P. S. Aspectos técnicos da utilização da carepa gerada em processos siderúrgicos e tratada por desagregação ultra-sônica. Tecnologia em Metalurgia e Materiais, Vol. 3. n.2, p. 1-5, 2006.

DANTAS, T.L.P.; MENDONÇA, V.P.; JOSÉ, H.J. Treatment of textile wastewater by heterogeneous Fenton process using a new composite $\mathrm{Fe} 2 \mathrm{O} 3 /$ carbon. Chemical Engineering Journal, v. 118, 77-82, 2006.

JCPDS - Joint Commite on Powder Diffration Standars. International Center of Diffraction Data. Pensilvânia USA, 1994.

LIMA, L. H. M.; REIS, S. C.; BORGES, L. R. Aproveitamento de resíduo siderúrgico em blocos cerâmicos argilosos. E-xacta, v. 6, n. 2, p. 69-78, 2013.

MACHADO, L. L. Utilização de compósito carvão/Fe2O3 e pirita como catalisadores da peroxidação de efluentes têxteis. Dissertação de Mestrado. Engenharia Química - Universidade Federal de Santa Catarina. Florianópolis, SC, 2007.

MARTINS, F. M. Caracterização Química e Mineralógica de Resíduos Sólidos Industriais Minerais do Estado do Paraná. Dissertação de 
Mestrado. Química - Universidade Federal do Paraná. Curitiba, PR, 2006.

MELO, A. R. Otimização do reuso de água em lavadores contínuos da indústria têxtil.

Florianópolis: Centro Tecnológico da Universidade Federal de Santa Catarina, 2005.

NEYENS, E.; BAEYENS, J. A review of classic

Fenton's peroxidation as an advanced oxidation technique. Journal of Hazardous Materials, v 98, n13, p 33-50, 2003.

OLIVEIRA, L. C. A.; FABRIS, J. D.; PEREIRA, M. C. Óxidos de ferro e suas aplicações em processos catalíticos: uma revisão. Química Nova, Vol. 36, 123130, 2013.

PARSONS, S. Advanced Oxidation Process of Water and Wastewater Treatment. Tumbridge Wells: IWA Publishing, 2004. 